\title{
Stress and Alcohol Cues Exert Conjoint Effects on Go and Stop Signal Responding in Male Problem Drinkers
}

\author{
Martin Zack*,1,2, Tracy M Woodford', Anne M Tremblay', Lindsay Steinberg', Laurie A Zawertailo ${ }^{1,2}$ \\ and Usoa E Busto ${ }^{1,2}$ \\ 'Centre for Addiction and Mental Health, Toronto, Ontario, Canada; '2Department of Pharmacology, University of Toronto, Toronto, Ontario, \\ Canada
}

\begin{abstract}
Stress, cues, and pharmacological priming are linked with relapse to addictive behavior. Increased salience and decreased inhibitory control are thought to mediate the effects of relapse-related stimuli. However, the functional relationship between these two processes is unclear. To address this issue, a modified Stop Signal Task was employed, which used Alcohol, Neutral, and Non-Words as Go stimuli, and lexical decision as the Go response. Subjects were 38 male problem drinkers (mean Alcohol Dependence Scale (ADS) score: 18.0). Uncontrollable noise ( $10 \mathrm{~min}$ at $110 \mathrm{~dB}$ ) was the stressor; nonalcoholic placebo beer (P-Beer) was the cue manipulation, and alcohol (0.7 g/ $/ \mathrm{kg})$, the pharmacological prime. Half the sample received alcohol, and half P-Beer. Stress and beverage (test drink vs soft drink) were manipulated within subjects on two sessions, with half the sample receiving active manipulations together and half receiving them separately. Go response time (RT) and Stop Signal RT (SSRT) were slower to Alcohol than Neutral words. Stress augmented this bias. Alcohol and P-Beer impaired overall SSRT. Stress impaired neither overall SSRT nor Go RT. SSRT to Neutral words and Non-Words correlated inversely with Go RT to Alcohol and Neutral words, and Non-Words. ADS correlated directly with SSRT to Alcohol words. A resource allocation account was proposed, whereby diversion of limited resources to salient cues effectively yoked otherwise independent Go and Stop processes. Disturbances of prefrontal norepinephrine and dopamine were cited as possibly accounting for these effects. Treatments that optimize prefrontal catecholamine transmission may deter relapse by reducing disinhibitory effects of salient eliciting stimuli.

Neuropsychopharmacology (20II) 36, 445-458; doi:I0.1038/npp.2010.177; published online 6 October 2010
\end{abstract}

Keywords: stress; alcohol; stop signal; salience; inhibitory control; catecholamines

Relapse is a critical challenge in the management of addictive behavior (Stewart, 2008; Witkiewitz and Marlatt, 2007). Stress and exposure to drug-related cues are common relapse triggers (Shaham et al, 2003; Sinha and Li, 2007). Neuroimaging studies suggest that cognitive processes mediate the effects of relapse triggers ( $\mathrm{Li}$ et al, 2008; Volkow et al, 2004). Experimental procedures have been developed to assess these processes (Eisenberg et al, 2007; Goldstein and Volkow, 2002). Addiction-related pictures and words elicit involuntary attention (Field et al, 2005; Hester et al, 2006), and activate reward-related brain circuitry in addicted individuals (Grusser et al, 2004; Heinz et al, 2004), reflecting their incentive salience. Addicted individuals also perform poorly on experimental measures of impulsivity, a tendency augmented by doses of their addictive substance (Bjork et al, 2004; Fillmore et al, 2006).

\footnotetext{
*Correspondence: Dr M Zack, Centre for Addiction and Mental Health, 33 Russell Street, Toronto, Ontario, M5S 2SI, Canada, Tel: (4I6) 535-850I, ext. 6052, Fax: (4I6) 595-6618,

E-mail: martin_zack@camh.net

Received 25 April 2010; revised 3 August 2010; accepted I September 2010
}

Impulsivity is multidimensional in terms of component processes and neural substrates (Crews and Boettiger, 2009; Evenden, 1999). Insensitivity to negative outcomes and impaired inhibitory control are two processes that have been successfully modeled, in Go/No-Go (GNG) and StopSignal task (SST), respectively (Eagle et al, 2008). The GNG taps 'passive avoidance learning:' learning to withhold a response to avoid punishment (Newman et al, 1985). The SST taps inhibition of a pre-potent response-ability to countermand a speeded decisional response to visual Go stimuli (eg, ' $\mathrm{x}$ ' or ' $\mathrm{o}$ ') when faced with an unexpected auditory Stop Signal (Logan et al, 1997).

The GNG and SST discriminate between addicted individuals and controls, suggesting that these tasks may operationalize key addiction-related inhibitory deficits (Kamarajan et al, 2005; Lawrence et al, 2009). However, inhibitory performance is also sensitive to situational factors. In healthy subjects, loud noise impairs inhibition of attention, as reflected by slower responses to incongruent color words (eg, BLUE printed in red) in a Stroop task (Hartley and Adams, 1974). Subjective stress positively predicts electrophysiological response to Go stimuli on the GNG in healthy subjects, whereas arousal negatively 
predicts electrophysiological response to No-Go stimuli (Brown et al, 1989). In problem drinkers, Alcohol words evoke more commission errors than Neutral words on a modified GNG task (Noel et al, 2007). Thus, stress and salient eliciting stimuli significantly moderate performancebased measures of impulsivity.

The GNG and SST engage both common (Bissett et al, 2009; Rubia et al, 2001) and distinct processes and neural systems (Andres, 2003; Eagle et al, 2008). It is unclear, therefore, whether salience would also affect impulsivity on the SST. Furthermore, the 'horserace' model of the SST posits that Go and Stop processes are independent: Go and Stop processes race against one another in parallel, with the winner determining the outcome. If the Go process wins, the overt response is committed, and if the Stop process wins, the response is withheld (Band et al, 2003). Empirical data largely support the model, although refinements have been proposed (Boucher et al, 2007; Verbruggen and Logan, 2009). These data were obtained on the standard SST, where the salience of Go stimuli was not manipulated. However, the literature suggests that salient Go stimuli may also impair inhibition on the SST, and that stress may augment this effect. Parallel effects of stress and salient cues on Go and Stop responses would suggest a functional relationship between Go and Stop processes.

This study investigated this question with a modified Stop Signal Task (MSST). Go stimuli were Alcohol words, Neutral words, or pronounceable Non-Words (eg, glimp); the Stop Signal was a tone. The Go task was speeded lexical decision, a standard index of semantic processing. For each category of Go stimuli, a random $25 \%$ of trials presented the Stop Signal. Per the original paradigm (Logan et al, 1997), an algorithm tracked inhibitory success, enabling computation of separate Stop Signal response time (SSRT) for each class of Go stimuli.

Subjects were male problem drinkers who performed the task on two sessions. Half received alcohol and the other half an alcohol cue (nonalcoholic placebo beer (P-Beer)). Half received stress (uncontrollable noise) and test drink (alcohol or P-Beer) on one session and control treatments (controllable noise, soft drink) on the other session (Combined Condition); the other half received one active and one control treatment on each session (Separate Condition).

It was predicted that Alcohol words would impair inhibitory control (slower SSRT) relative to Neutral words. Stress, cues (P-Beer), and alcohol were each expected to augment this bias. The relationship between Go and Stop processes was assessed in terms of concordant effects of experimental factors on Go RT and SSRT, and the correlation between these two RT indices.

\section{MATERIALS AND METHODS}

\section{Subjects}

A total of 40 male problem drinkers (ages 21-61 years) were recruited by newspaper advertisements. They scored $\geqslant 13$ on the Alcohol Dependence Scale (ADS) (Skinner and Allen, 1982), the second quartile for this population (Skinner and Horn, 1984). Subjects scored $<10$ on the Beck Depression Inventory-short form (BDI-sf) to rule out clinical depression (Beck and Beck, 1972), and were physically healthy based on a physician's exam. The final sample included 38 subjects: 18 in the Alcohol group and 20 in the P-Beer group. (Two subjects in the Alcohol group displayed inhibitory error rates on the MSST that were unduly high (case 1: 95\% commission errors to Alcohol words on session 1; case 2: $72 \%$ commission errors to Neutral words on session 1, and $70 \%$ errors to both Alcohol and Neutral words on session 2). The algorithm is designed to yield an inhibitory error rate of $\sim 50 \%$, such that the derived value of SSRT (mean Go RT-mean SS delay) corresponds to the mean of the Stop RT distribution. The very high error rates of these two cases indicate that their distribution of Stop RT scores did not overlap with their distribution of Go RT scores sufficiently to achieve $50 \%$ inhibitory success. As such, SSRT is not a valid measure of central tendency for the Stop RT distributions of these subjects. Accordingly, their data were excluded from the analyses.) All had normal or corrected-to-normal vision and high school English proficiency. They received $\$ 300$ upon completion.

\section{Apparatus}

The Timeline Followback (TLFB) (Sobell et al, 1996) measured alcohol use in the preceding 90 days. The nineitem Eysenck Impulsivity scale (Eysenck and Eysenck, 1969) measured trait Impulsivity, per the original SST study (Logan et al, 1997). Visual analog scales (VAS) (Fischman and Foltin, 1991) measured Desire for Alcohol and perceived Stress (0-100; none-extreme) at baseline, postnoise (stressor), and post-drink/post-MSST. A Drink Strength Rating scale assessed the credibility of the P-Beer. Subjects estimated their dose in standard (355 $\mathrm{ml}$ at $5 \%$ ) bottles of beer (Vogel-Sprott, 1992).

A J4X-ALERT breathalyzer (Alcohol Countermeasures, Mississauga, ON, Canada) assessed blood alcohol concentration (BAC) at baseline, 20 min after drink completion, and immediately before and after the MSST. The alcohol dose $(0.7 \mathrm{mg} / \mathrm{kg})$ consisted of vodka (40\%) and orange juice, mixed in a $1: 3$ ratio delivered in two equal portions, 20 min apart.

The P-Beer consisted of two 355-ml cups of alcohol-free 'Nordic' beer (Labatt Brewing, Toronto, ON, Canada). Drinks were chilled thoroughly to deter detection of the lack of alcohol. To enhance the credibility of the manipulation, P-Beer subjects received a mock breathalyzer test 10 min after they completed their second drink. The device registered a false BAC of $0.041 \%$ (Martin et al, 1990). Thus, for P-Beer subjects, 'placebo' beer was the active drink manipulation. The control beverage for all subjects was diet soft drink (Fresca, Coca-Cola, Toronto, ON, Canada), not commonly used as drink mix, to minimize cues for alcohol, served in two $355 \mathrm{ml}$ drinks, $20 \mathrm{~min}$ apart.

A wrist cuff (HEM-601; Omron, Vernon Hills, IL) monitored heart rate (HR) at baseline, before and after the noise task, at post-drink/pre-MSST, and post-MSST.

\section{Stressor}

The stressor consisted of 10-min uncontrollable white noise (110 dB; 2-20 s bursts) delivered at random intervals through headphones. This procedure activates the hypothalamic 
pituitary axis in healthy subjects (Breier et al, 1987), and induces significantly greater distress than a control condition that delivers 10-min controllable noise (Richell and Anderson, 2004). Subjects sat facing a computer screen at a distance of $\sim 60 \mathrm{~cm}$. They were told they would hear a loud noise, which may be uncomfortable but was not harmful. They were told that their job was to stop the noise by determining the correct sequence/timing of mouse clicks on a circular target on the screen. They first performed the control version of the task, in which noise can be terminated by clicking on the target four times in rapid succession. The screen then flashed 'Subject-Out', indicating the subject had successfully stopped the noise.

In the uncontrollable (active stress) version, visual targets cannot be extinguished. Instead, they disappear at random intervals, and noise continues the entire time the target is displayed. When the target extinguishes, the message 'Timeout' appears, indicating the subject exceeded the time limit, and the computer automatically timed out.

In both task versions, subjects were led to believe that they could terminate the noise. This was reinforced with an initial block of controllable trials. Subsequent blocks $(2 \times 25$ trials at $5 \mathrm{~min}$ ) manipulated noise controllability (ie, stress).

\section{MSST}

The task was administered on a PC (visual distance $\sim 60 \mathrm{~cm}$ ). Instructions were presented orally and on the screen. The task consisted of a series of speeded lexical decision trials, each presenting a visual target (letter string) in the center of the screen. On each trial, the subject was to press one of two keys as quickly and accurately as possible: ' $\mathrm{z}$ ' with the left forefinger for Non-Words (eg, glimp), or ' $/$ ' with the right forefinger for real words. Equal numbers of real words (120 Alcohol, eg, whisky; 120 Neutral, eg, window) and Non-Words (240) were administered. Stimulus categories were matched on length, frequency of occurrence in print, and concreteness (Kucera and Francis, 1967; Wilson, 1988). All stimuli were taken from previous studies (Zack et al, 1999a, b). (The full list of stimuli is available from $M Z$ upon request.)

The Stop signal occurred on a random $25 \%$ of trials for each class of Go stimuli, enabling derivation of separate SSRT for each class. The procedure conformed closely to the original (x/o) version (Logan et al, 1997). Events on every trial were the same: fixation stimulus $(++++$; $500 \mathrm{~ms}$, center of screen)/1000 ms blank/letter string $(1000 \mathrm{~ms}$ Go signal; 18-pt font)/1000 ms blank.

On Stop trials, a tone $(1000 \mathrm{~Hz}, 100 \mathrm{~ms})$ sounded at varying delays after onset of the Go stimulus. The interval between the onset of Go and Stop signals (SS delay) was initially set at $350 \mathrm{~ms}$, somewhat longer than the $250 \mathrm{~ms}$ used in the original SST, reflecting the longer time required to make a lexical $v s$ orthographic (x/o) decision. The algorithm varied SS delay over stop trials. If the subject successfully withheld his response, SS delay increased by $50 \mathrm{~ms}$, making inhibition on the next Stop trial more difficult; if the subject failed to withhold his response, SS delay decreased by $50 \mathrm{~ms}$, making inhibition on the next Stop trial less difficult. Thus, over the 30 Stop trials for each Word Type, and 60 Stop trials for Non-Words, the algorithm progressively refined SS delay to identify the interval associated with 50\% inhibitory success. The SS delay used to compute SSRT was the average delay over all Stop trials for each stimulus category (Logan et al, 1997).

Categories and items were randomized over 560 trials: eight 70 -trial blocks, with $30 \mathrm{~s}$ rests between blocks. Subjects first performed 20 practice trials with two sets of Neutral words, $50 \%$ Non-Words, and $25 \%$ Stop trials. The entire task took $\sim 20 \mathrm{~min}$.

\section{Study Design}

Figure 1 shows the study design: subjects were matched on severity of dependence (ADS), randomized to Alcohol or P-Beer Drink group, and assigned to one of four treatment conditions. To preclude habituation to the stressor or detection of the placebo, each subject received the active version of each manipulation only once. Subjects in Combined conditions received Stress + Test Drink together on one session and No-Stress control task (Controllable Noise) + Control Drink on the other. Subjects in Separate conditions received Stress + Control Drink together on one session and No-Stress + Test Drink on the other. Treatment sequence $(A, B)$ was counterbalanced across subjects in each condition.

\section{Procedure}

The study conformed to the principles of the Helsinki Declaration (1989), and was approved by the research ethics board of the Centre for Addiction and Mental Health $(\mathrm{CAMH})$. Volunteers were screened by phone against initial inclusion/exclusion criteria. Prospective subjects attended an interview, which included written informed consent, trait scales, blood/urine drug screens, and scheduling of the physician's exam. Eligible subjects attended two identical (apart from stress/drink) test sessions, held at least 2 days apart, that began at 1100 hours and ran for $\sim 4 \mathrm{~h}$. Subjects were instructed not to drink alcohol for at least $12 \mathrm{~h}$ and to eat a light meal $2 \mathrm{~h}$ before each session.

The sequence of events in test sessions was identical: verbal overview; advisory of drink condition (Test, Control); Baseline Measures: BAC 0, VAS (Desire for Alcohol, Perceived Stress), HR; pre-noise HR; noise task (Stressor); post-noise VAS/HR; Drinks 1, 2 (20-min interval); BAC 1 (post-drink 2); BAC 2 (pre-MSST); Pre-MSST HR; MSST; BAC 3 (post-MSST) VAS/HR; lunch; BAC $4(\leqslant 0.03 \%)$; departure (taxi); debriefing (day 2); optional alcohol treatment referral (at CAMH; day 2); and payment (by check $\sim 2$ weeks later).

On Test Drink days, P-Beer subjects were told that they would receive beer, but were not told that it was alcohol free. They provided Drink Strength Ratings just before departure. The MSST began $50 \mathrm{~min}$ after drinking commenced and ended $\sim 20$ min later, which was designed to coincide with the ascending limb and peak BAC. Upon departure, Alcohol subjects were instructed not to drive for $6 \mathrm{~h}$.

\section{Data Analytic Approach}

RT (ms) and response accuracy (\%) were analyzed with 2 (Response Type: Go, Stop) $\times 2$ Word Type (Alcohol, Neutral) $\times 2$ (Drink Group: Alcohol, P-Beer) $\times 2$ (Stress: Present, Absent) $\times 2$ Treatment Condition (Combined, 


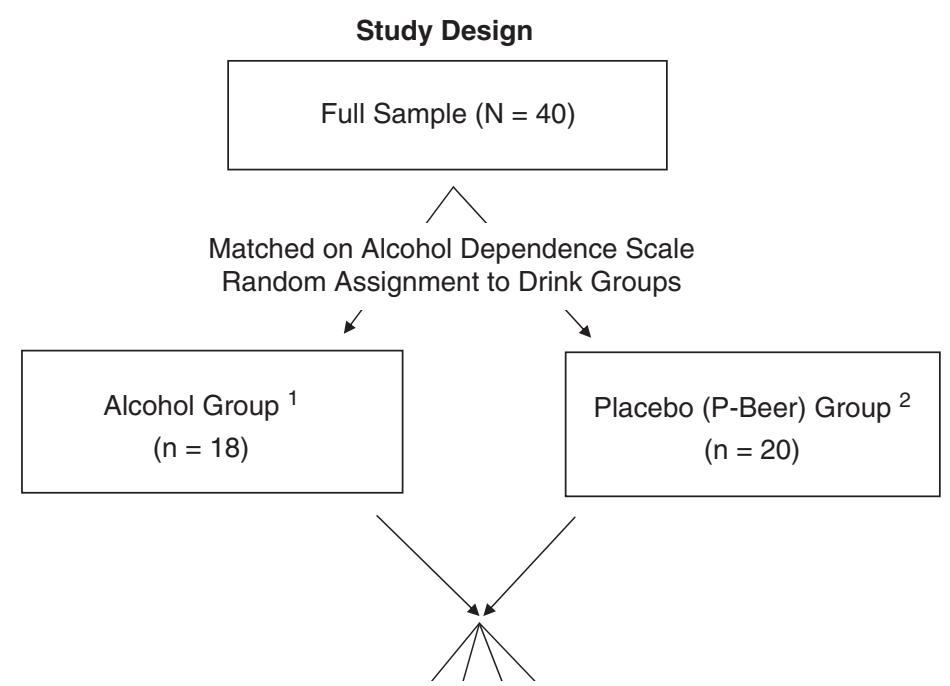

Random Assignment

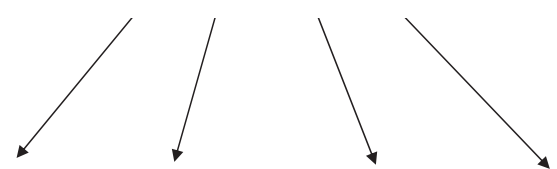

Test Session ${ }^{3}$

Treatment Condition

\begin{tabular}{|l|l|l|l|c|}
\hline & \multicolumn{1}{|c|}{ Combined A } & \multicolumn{1}{|c|}{ Combined B } & Separate A & Separate B \\
\hline 1 & Stress + Test Drink & No Stress + Control Drink & Stress + Control Drink & No Stress + Test Drink \\
\hline 2 & No Stress + Control Drink & Stress + Test Drink & No Stress + Test Drink & Stress + Control Drink \\
\hline
\end{tabular}

1 Two subjects excluded due to extreme error rates

2 Placebo = Alcohol-free Beer (P-Beer)

${ }^{3}$ Test Session $=$ Within-subjects

Figure I Subject assignment procedure and study design.

Separate) ANOVAs. ANOVAs with the same factors (except Word Type) analyzed Non-Word RT and accuracy. To control for possible speed-accuracy tradeoff, RT was also assessed by ANCOVA, controlling for accuracy. VAS were assessed with ANCOVA, including Time (Post-Noise, Post-Drink/Post-MSST), and controlling for baseline. Simple effects decomposed significant interactions (Winer, 1971). Correlations assessed relationships between Go RT and SSRT, along with Impulsivity and ADS. Unlike the ANOVAs, variance due to treatment sequence and repetition effects could not be adequately controlled in the correlational analyses. Therefore, separate correlations were computed for each session.

\section{RESULTS}

\section{Subject Characteristics}

Table 1 shows the subject characteristics for the Alcohol and $\mathrm{P}$-Beer groups. ANOVAs for the five indices revealed a higher BDI-sf score in the P-Beer group $(\mathrm{F}(1,30)=4.63$,
Table I Background Characteristics for Community-Recruited Male Problem Drinkers Who Received Alcohol $(0.7 \mathrm{~g} / \mathrm{kg}$ ) or Non-Alcoholic Placebo Beer (P-Beer) as Their Test Drink

\begin{tabular}{lcc}
\hline Index & \multicolumn{2}{c}{ Group } \\
\cline { 2 - 3 } & Alcohol & P-Beer \\
\hline$N$ & 18 & 20 \\
Age & $37.7(12.1)$ & $38.7(11.8)$ \\
Drinks per week & $33.7(10.5)$ & $27.6(10.2)$ \\
Alcohol Dependence Scale & $17.9(5.0)$ & $18.1(4.9)$ \\
Beck Depression Inventory-sf & $5.9(2.7)$ & $7.7(2.6)^{\mathrm{a}}$ \\
Eysenck Impulsivity Scale & $5.5(2.8)$ & $4.7(2.0)$
\end{tabular}

aMain effect of Drink group, $p<0.05$.

Soft drink was the control beverage for all subjects.

$p=0.040$ ), and no other significant effects. Thus, groups were generally well matched. The BDI-sf scores of both groups fell below the cutoff of 10 for clinical depression 
Table 2 Summary of Significant Experimental Effects

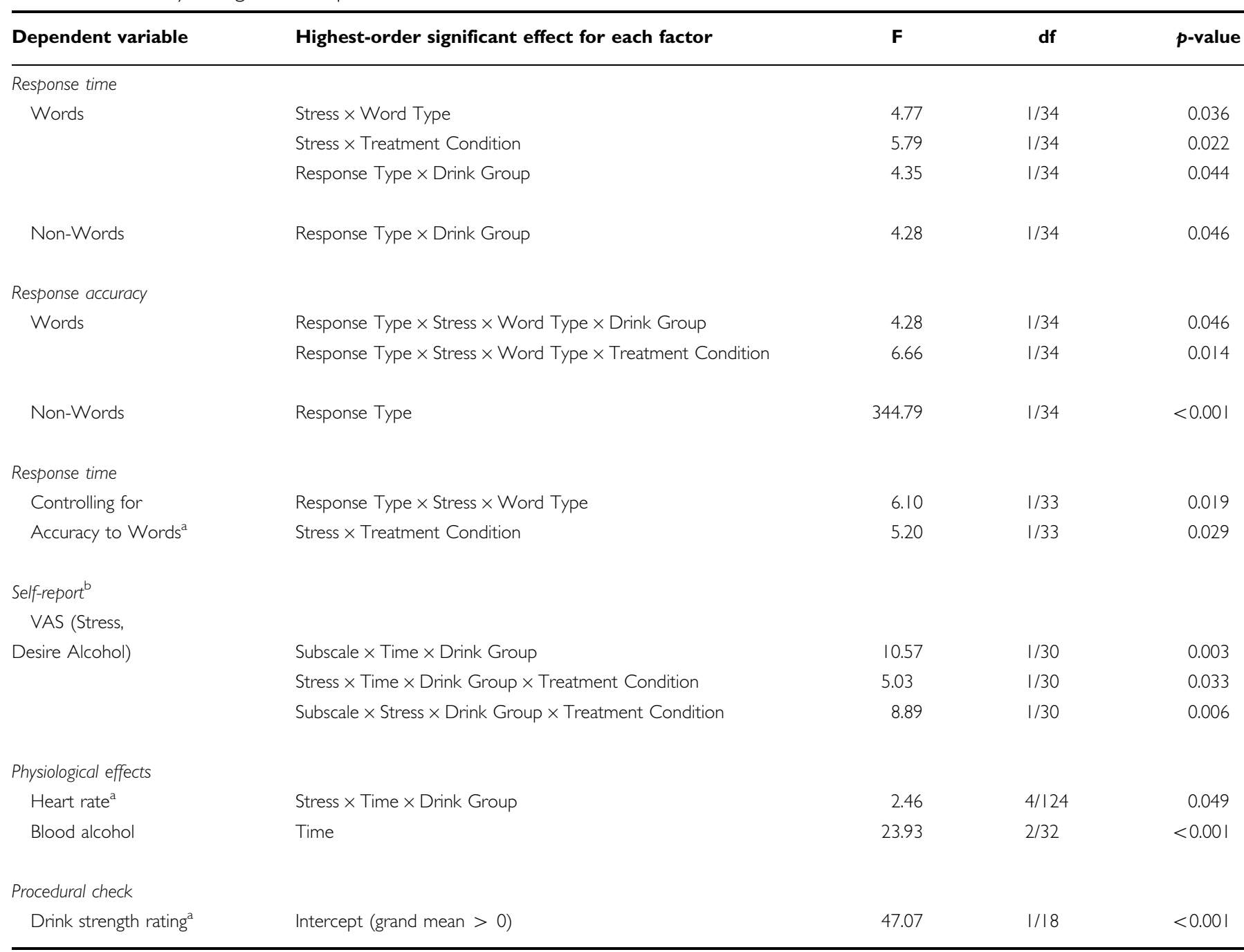

aPlease see Supplementary Material and Methods at Neuropsychopharmacology website.

${ }^{\mathrm{b}}$ Analyzed by ANCOVA of Visual Analog Scale (VAS) scores for each subscale (Desire for Alcohol, Perceived Stress) at Post-Noise and Post-Drinking, controlling for session (Pre-Noise) baseline.

Stress (Present, Absent); Word Type (Alcohol, Neutral); Treatment Condition (Combined: Active Stress + Test Drink on same session; Separate: Active Stress and Test Drink on separate sessions); and Drink Group (Test Drink: Alcohol vs. Placebo Beer; P-Beer).

(Furlanetto et al, 2005). The sample was comprised of mature adults, with 'moderate' levels of alcohol consumption based on norms for problem drinkers (Wilkinson and LeBreton, 1986), and 'moderate' levels of alcohol dependence (second quartile) based on norms for the ADS (Skinner and Horn, 1984). Eysenck scale scores also indicated moderate trait Impulsivity, relative to the maximum score of 9 .

\section{Task Performance}

Go RT and SSRT to Alcohol and Neutral words. Table 2 reports the highest-order significant effects for the experimental outcome measures. The table shows that the ANOVA of RT scores yielded three significant interactions. The Stress $\times$ Word Type interaction was the principal result. Figure 2 presents the means for each level of Stress and Word Type and reveals that the two-way interaction reflected significantly $(p<0.01)$ larger SSRT and Go RT to
Alcohol vs Neutral words when subjects received Stress as opposed to the No-Stress control task. Thus, Stress was associated with slower overt choice responses and slower inhibition of responses to Alcohol than Neutral words. Response Type (Go/Stop) did not significantly moderate this effect $(p>0.10)$, indicating that Stress had a comparable biasing effect on Go RT and Stop RT (for follow-up analysis of covariance, controlling for accuracy rates, please see Supplementary Materials and Methods).

The main effect of Word Type was also significant $(\mathrm{F}(1,34)=20.43, p<0.001)$, and was not moderated by Response Type $(p>0.60)$. This reflected slower overall mean (SEM) RT for both Go and Stop responses to Alcohol words $(\mathrm{Go}=862$ (34); Stop $=286(13) \mathrm{ms}$ ) than to Neutral words $(\mathrm{Go}=839$ (32); Stop $=267$ (11) ms).

The Stress $\times$ Treatment Condition interaction reflected the effects of Stress and Drink (Test $v s$ Control) on overall RT. The two-way interaction was not moderated by 


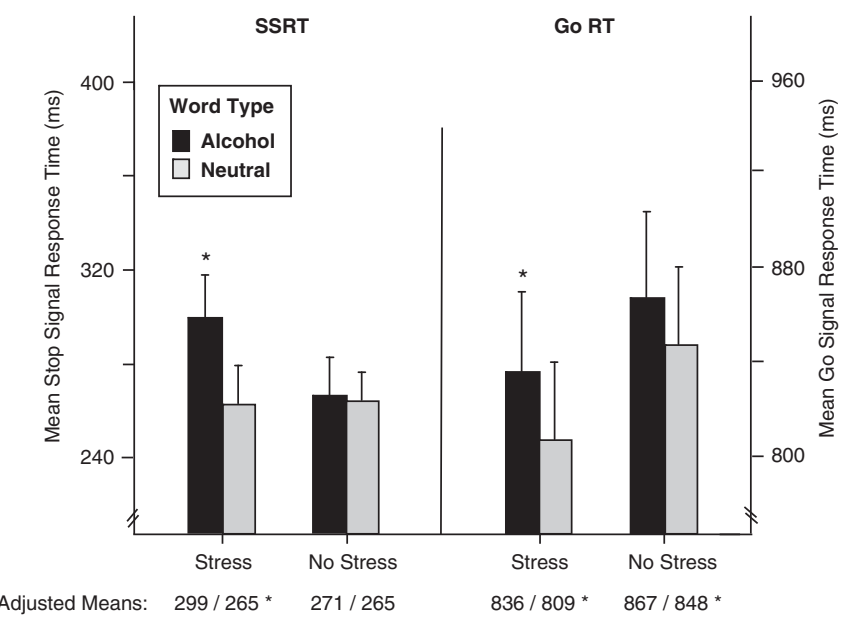

Figure 2 Mean (SEM) Stop Signal response time (SSRT; ms) and Go RT to Alcohol and Neutral word stimuli in male problem drinkers $(n=38)$. Adjusted means below $x$-axis are derived from analysis of covariance of $\mathrm{Go}$ RT and SSRT, controlling for Go and Stop response accuracy (see Supplementary Material and Methods). Asterisks denote simple effect of Word Type (Alcohol vs Neutral), $p<0.05$.

Response Type, Word Type, or Drink Group ( $p>0.16$ for all). In the Alcohol Group, the No-Stress + Test Drink condition was associated with slower $(p<0.001)$ overall SSRT (335 (31) ms, and Go RT, 842 (82) ms) than the NoStress + Control Drink (no-treatment) condition (236 (25) $\mathrm{ms}$ and 762 (65) ms). In contrast, Stress + Control Drink was not associated with significantly different overall SSRT (260 (31) ms, or Go RT 796 (79) ms) than the no-treatment control. Stress + Test Drink combined yielded equivalent overall SSRT (351 (29) ms) but faster $(p<0.05)$ Go RT (735 (63) $\mathrm{ms})$ relative to No-Stress + Test Drink. Thus, Alcohol significantly impaired overall Stop and Go responding relative to no-treatment, whereas Stress did not impair overall Stop or Go responding or augment the overall impairing effects of Alcohol.

In the P-Beer Group, the No-Stress + Test Drink condition was associated with slower $(p<0.05)$ overall SSRT (265 (26) ms), but equivalent Go RT (909 (69) ms) relative to No-Stress + Control Drink (no-treatment) condition (239 (26) ms and 919 (68) ms). Stress + Control Drink yielded equivalent $(p>0.08)$ overall SSRT $(263(31) \mathrm{ms})$ but faster $(p<0.001)$ Go RT $(858$ (66) ms) than the notreatment control. Stress + Test Drink combined yielded equivalent overall SSRT (252 (31) and Go RT 907 (66) ms) relative to No-Stress + Test Drink. Thus, P-Beer significantly impaired overall Stop but not Go responding relative to notreatment, whereas stress did not impair overall Stop or Go responding or augment the impairing effects of P-Beer.

Thus, across the two Drink Groups, the Stress $\times$ Treatment Condition interaction reflected a consistent impairing effect of Alcohol and P-Beer on SSRT and consistent lack of impairing effect of Stress on SSRT. Results for Go RT were more variable, in terms of significant effects of Test Drink as well as Stress. In sum, the Test Drink reliably impaired SSRT but not Go RT and Stress did not reliably impair either overall RT index.

The Response Type $\times$ Drink Group interaction reflected slower $(p<0.05)$ overall SSRT in Alcohol subjects (295 (17) $\mathrm{ms})$ than Placebo subjects (255 (15) ms), but faster overall
Go RT in Alcohol (784 (49) ms) than Placebo subjects (898 (45) $\mathrm{ms}$ ). This effect was not moderated by Stress or Treatment Condition $(p>0.13)$, and therefore cannot be attributed to either manipulation.

Go RT and SSRT to Non-Words. Table 2 shows that the ANOVA of Go RT and SSRT to Non-Words yielded a significant Response Type $\times$ Drink Group interaction. This did not interact with Stress or Treatment Condition $(p>0.12)$. Overall, Go RT was faster $(p<0.01)$ in the Alcohol group (857 (51) ms) than the P-Beer group (960 (47) $\mathrm{ms}$ ), whereas SSRT in the Alcohol group (355 (21) ms) did not differ from that of the P-Beer group (303 (19) ms, $p>0.10)$. The lack of interaction with other experimental factors precludes attribution of this effect to the Stress or Test Drink manipulation.

Response accuracy to Alcohol and Neutral words. Overall, Go accuracy (\%) was $\sim 92 \%$, indicating highly proficient overt response selection. Overall, Stop accuracy was $\sim 47 \%$, which was close to the expected ideal value of $50 \%$ inhibitory success for the algorithm. For analysis of accuracy rates as a function of Drink Group, Stress, and Treatment Condition, please see Supplementary Materials and Methods.

Response accuracy to Non-Words. The main effect of Response Type was the only significant result for NonWords (Table 2). Overall, Go accuracy was 92.2\%, and overall Stop accuracy was $57.9 \%$.

\section{Correlational Analyses}

Table 3 reports the Pearson correlations between SSRT and Go RT to Alcohol words, Neutral words, and Non-Words, along with the correlation between these scores, trait Impulsivity, and Alcohol Dependence (ADS). The diagonal scores show that SSRT and Go RT for each word type were generally inversely related, and that this inverse relationship was significant for Neutral words and Non-Words on test session 1. Notably, SSRT to Neutral words and Non-Words was also inversely correlated with Alcohol Go RT on session 1. On test session 2, the inverse directional relationship between SSRT and Go RT generally persisted, but its strength was greatly attenuated.

Correlations for SSRT to the different Word and NonWord stimuli were large and positive on session $1(r>0.80)$ and to a lesser extent on session $2(r>0.60)$. Correlations for Go RT to the different Word and Non-Word stimuli were large and positive on both sessions $(r>0.90)$. Thus, when SSRT to Word and Non-Word stimuli was assessed under the same conditions, a common process explained about two-thirds $\left((0.80)^{2}=64 \%\right)$ of the variance in inhibitory efficiency when subjects first encountered the stimuli, and about one-third $\left((0.60)^{2}=36 \%\right)$ of the variance when subjects had encountered the stimuli before. When Go RT to Word and Non-Word stimuli was tested under the same conditions, a common process explained more than four-fifths $\left((0.90)^{2}=81 \%\right)$ of the variance in psychomotor fluency, regardless of prior exposure to the stimuli.

Correlations for SSRT between sessions 1 and 2 were negligible for Alcohol and Neutral words, but substantial for 
Non-Words $(r=0.52, p<0.05)$. Thus, when testing occurred under different experimental (Stress/Drink) conditions, little variance in inhibitory control to verbal stimuli was explained by a common process, whereas more than onefourth $\left((0.52)^{2}=27 \%\right)$ of the variance in inhibitory control to meaningless stimuli was explained by a stable common process (ie, a trait factor). Correlations for Go RT between sessions 1 and 2 were strong and positive for all classes of stimuli $(r>0.80)$. Thus, when testing occurred under different conditions, substantial variance in psychomotor fluency was explained by a stable common process.

Trait Impulsivity correlated significantly with scores on the ADS, but Impulsivity itself did not correlate significantly with any aspect of task performance. However, ADS correlated positively with SSRT to Alcohol words in session 2. Thus, trait Impulsivity was associated with greater alcohol dependence, and greater dependence in turn was associated with poorer inhibitory control to Alcohol words encountered once before.

\section{Subjective Effects: Desire for Alcohol and Perceived Stress}

An initial ANOVA of baseline VAS scores yielded a Stress $\times$ Treatment Condition $\times$ Drink Group interaction $(\mathrm{F}(1,34)$ 4.91, $p=0.034)$, which was not moderated by VAS subscale $(p>0.80)$. Thus, subjects in the different conditions differed in their pre-test desire for alcohol and perceived stress levels. To control for this extra-experimental variance, an ANCOVA of VAS scores was performed on post-noise (stress) and post-drink/post-MFFT VAS ratings, with baseline VAS scores as covariates.

Table 2 shows that the ANCOVA yielded three significant interactions. The source of these effects can be determined from Figure 3, which presents the covariate-adjusted means for each subscale in the Alcohol group (Figure 3a) and P-Beer group (Figure 3b). Different superscripts denote scores that differed significantly $(p<0.05)$ from one another.

Figure $3 \mathrm{a}$ shows that in the Alcohol group, Desire for Alcohol was greater after the active stressor than the nostress control task when alcohol was expected (a vs c) but was greater after the no-stress control task when soft drink was expected (b vs c). Consumption of alcohol (solid lines) was associated with a greater increase in Desire for Alcohol than consumption of soft drink (dashed lines). The active stressor led to greater reported Stress than the no-stress control task when alcohol was expected (f $v s \mathrm{~g}$ ) but not when soft drink was expected (e). Drink consumption coincided with a significant decline in Stress ratings, except when subjects received alcohol after the no-stress control task (g $v s \mathrm{i}$ ), in which case drinking coincided with an increase in Stress ratings.

Figure $3 \mathrm{~b}$ shows the corresponding scores for the P-Beer group. The figure shows that there was no difference in Desire for Alcohol as a function of active stress $v s$ no-stress control (a). However, consumption of P-Beer (solid lines) reduced Desire for Alcohol more than consumption of soft drink (dashed lines) after the active stressor (a vs b), whereas consumption of soft drink reduced Desire for Alcohol more than consumption of P-Beer after the no-stress control. Expectation of P-Beer coincided with greater Stress ratings than expectation of soft drink, 
regardless of stress condition (c vs d). Consumption of P-Beer coincided with a significant decline in Stress ratings, whereas consumption of soft drink did not.

A comparison of Figure $3 \mathrm{a}$ and $\mathrm{b}$ suggests that the Subscale $\times$ Time $\times$ Drink Group interaction (Table 2) resulted from an opposite effect of Time (ie, drink consumption) on Desire for Alcohol in the Alcohol group (increase) $v s$ P-Beer group (decrease), but a parallel effect of Time (decrease) on perceived Stress in both Drink groups. The Stress $\times$ Time $\times$ Drink Group $\times$ Treatment Condition interaction occurred because consumption of Alcohol alone (ie, No Stress + Test Drink) (Figure 3a; solid lines + clear circles) led to a parallel increase over Time in Desire for Alcohol and in subjective Stress. In the other conditions, Time had directionally opposite effects on the two VAS subscales in the Alcohol group, whereas Time had parallel effects on each VAS Subscale in the P-Beer group.

The Subscale $\times$ Stress $\times$ Drink Group $\times$ Treatment interaction reflected a difference in the overall size of VAS scores, collapsed across Time in the two Drink groups. In the Alcohol group, Desire for Alcohol was significantly greater $(p<0.001)$ in the Stress + Test Drink condition (41.5 (5.6)) than in the other three Stress $\times$ Treatment Conditions (20.6 (7.7)-25.9 (5.0)). Thus, the combined active treatments had additive effects on Desire for Alcohol. For Stress, VAS ratings were greater $(p<0.05)$ for Stress + Soft Drink (25.6 (5.0)) than No-Stress + Soft Drink (20.3 (4.1)) but did not differ for Stress + Test Drink (16.3 (3.6)) vs No-Stress + Test Drink (12.9 (5.7)). Thus, the combined active treatments had overall countervailing effects on selfreported Stress. In other words, consumption of alcohol negated the subjective stressful effects of uncontrollable noise.

In the P-Beer group, overall Desire for Alcohol was greater $(p<0.05)$ in the No-Stress + Test Drink condition (38.7 (5.4)) than in all other conditions (33.7 (5.4)-36.0 (6.0)). Thus, P-Beer alone coincided with greater Desire for Alcohol than Soft Drink alone, and Stress did not augment the effects of either beverage. VAS Stress ratings were greater $(p<0.05)$ for Stress + Test Drink $(18.7(4.0))$ than for all other conditions (12.3 (3.9)-15.5 (4.5)), which did not differ from one another. Thus, P-Beer and the active stressor had additive effects on subjective Stress.

In sum, actual alcohol primed motivation for alcohol to a greater extent after stress and this effect was associated with a decline in subjective stress. Conversely, placebo alcohol primed motivation for alcohol to a greater extent in the absence of stress, and this effect was associated with an increase in subjective stress.

\section{Heart Rate}

Overall mean (SEM) post-noise heart rate (beats/min) was greater following stress, 68.2 (2.2) than no-stress control, 65.3 $(2.5), t(31)=2.95, p<0.01$. However, the pattern of effects was moderated by drink group (Table 2). Higher order effects of stress and drink manipulations are reported in Supplementary Material and Methods.

\section{BAC}

The ANOVA of BAC scores at post-drinking, pre-MSST, and post-MSST yielded a significant main effect of Time
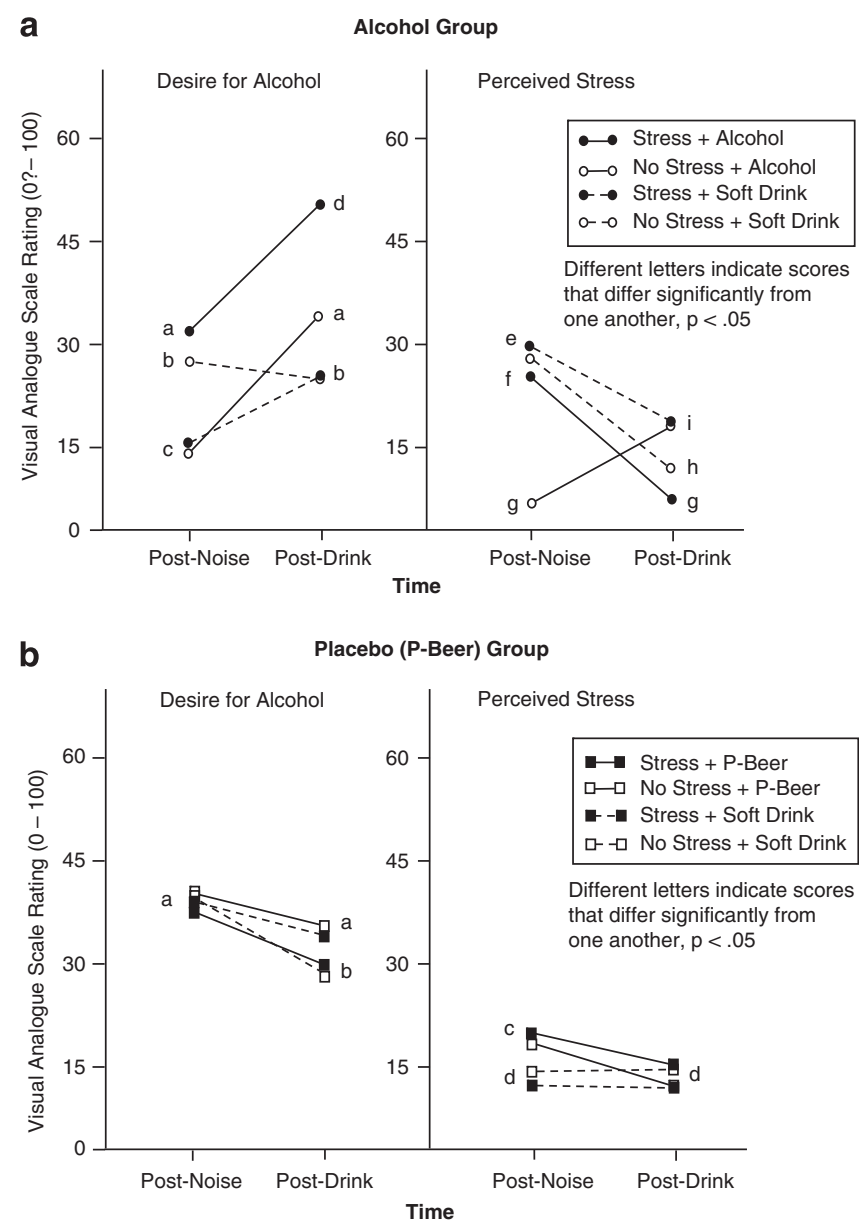

Figure 3 Visual analog scale (VAS; 0-100: none-extreme) ratings of Desire for Alcohol and perceived Stress at post-noise task and post-drink/ post-modified Stop Signal Task. (a) Scores for subjects $(n=18)$ who received alcohol (solid lines) vs soft drink (dashed lines) combined with the active stressor (filled circles) or non-stress control task (clear circles) are shown. (b) Scores for subjects $(n=20)$ who received alcohol-free placebo beer (P-Beer; solid lines) or soft drink (dashed lines) combined with the active stressor (filled squares) or non-stress control task (clear squares) are shown.

(Table 2) and no other significant effects ( $p>0.59$ for all). Mean (SEM) BAC was $0.047 \%$ (0.007) immediately before the task and $0.066 \%(0.005)$ immediately after the task, which corresponded to peak BAC.

\section{DISCUSSION}

This study examined the cognitive-behavioral and subjective effects of stress, conditioned cues for alcohol, and alcohol itself in male problem drinkers. The goal was to see how these relapse-related factors influence psychomotor fluency and inhibitory control when eliciting stimuli had high incentive salience or were motivationally neutral. In line with the primary hypothesis, Alcohol words consistently led to slower SSRT and Go RT scores than Neutral words did. This effect was observed in the same subjects on separate sessions as well as in between-group comparisons of subjects who received alcohol vs P-Beer. These results demonstrate that the salience of eliciting stimuli reliably alters the efficiency of both Stop and Go processes in subjects for whom these stimuli have high incentive value. 
Of the relapse-related variables, only stress moderated the effects of word type: the relative slowing of SSRT to Alcohol $v s$ Neutral words was more pronounced under stress than no stress. Thus, stress amplified a deficit in inhibitory control to salient eliciting stimuli.

The Test Drink alone led to slower overall SSRT relative to the soft drink control. The Test Drink effects were consistent across groups and conditions for SSRT, but more variable for Go RT. On the conventional SST, alcohol impairs inhibitory control in social drinkers, whereas placebo alcohol does not (Mulvihill et al, 1997). The present results suggest that placebo alcohol may impair overall inhibitory control to verbal stimuli in problem drinkers. Differences in the cognitive demands of the Go task (ie, semantic $v s$ orthographic processing) on the MSST $v s$ conventional SST, as well as stronger responses to conditioned alcohol cues in problem drinkers, may contribute to the effects of the placebo on the MSST in this study.

In contrast to the Test Drink manipulation, Stress alone did not significantly impair overall SSRT relative to the nostress control in either Drink group. This suggests that Stress may primarily act to moderate the effects of a preexisting bias in inhibitory control to salient stimuli. It is also possible that the controllable noise task that represented the 'no-stress' condition induced some degree of stress itself, making it difficult to detect the augmenting effect of uncontrollable noise (Active Stressor). As noted earlier, modest exposure to white noise per se can impair inhibitory control on a Stroop task (Hartley and Adams, 1974), and has been found to activate the hypothalamic pituitary axis in rats (Samson et al, 2007). In the present study, the Alcohol group exhibited a modest HR increase after both controllable and uncontrollable noise (see Supplementary Materials and Methods), in line with the possibility that controllable noise elevated physiological stress levels to some degree. Future research could explore this possibility by including a true null (ie, no noise) condition.

The amplifying effect of stress on relative SSRT to Alcohol vs Neutral words also emerged on Go RT. This effect persisted (and actually increased) when variability in response accuracy was controlled by analysis of covariance (see Supplementary Materials and Methods). These results indicate that stress exerted concordant effects on Stop and Go processes, as measured by relative RT to salient $v s$ neutral eliciting stimuli.

The correlational analyses complemented the analyses of mean effects. Across individuals, faster Go RT was generally associated with slower SSRT. This pattern was more pronounced on session 1 , when practice effects were minimal. In addition, the inverse relationship was more pronounced between SSRT to Neutral words or Non-Words and Alcohol Go RT rather than between SSRT and Go RT to Alcohol words alone. This suggests that the inverse relationship did not arise from a direct conflict between approach (Go) and avoidance (Stop) to salient stimuli. Instead, the pattern is more consistent with the possibility that salient stimuli diverted cognitive resources normally used to inhibit ongoing behavior. As a result, the pre-potent Go process was more likely to prevail despite the occurrence of the Stop signal. If so, salience may not lead directly to 'loss of control' to Alcohol stimuli so much as it predisposes one to commit other responses (eg, inappropriate speech, driving infractions) one would normally withhold (Field and Quigley, 2009; Field et al, 2008; Finn et al, 1999; Townshend and Duka, 2007). Put simply, preoccupation may promote disinhibition.

The correlational results were also noteworthy with respect to trait factors. Initial research with the standard SST found a significant correlation $(r=0.315)$ between Impulsivity on the Eysenck scale and SSRT in a heterogeneous sample of healthy volunteers $(N=136$; Logan et al, 1997). In line with this, the present study observed correlations between Impulsivity and SSRT of 0.25-0.29 to the three types of Go stimuli in session 2, although the smaller $N$ in the present study rendered these correlations nonsignificant. Also in line with the original study, Impulsivity had no relationship with Go RT in any condition. The size of the correlations in this study indicates similar shared variance between trait Impulsivity and inhibitory control in problem drinkers and healthy volunteers.

The significant correlation between scores on the ADS and SSRT to Alcohol words in session 2 was also noteworthy. The correlation between ADS and Alcohol word SSRT in session 1 was the next largest for any performance index. There was no correlation between ADS scores and SSRT to Neutral or Non-Word stimuli in either session. Thus, severity of alcohol dependence and inhibitory control to alcohol stimuli appear to tap a common construct. This is consistent with the Incentive Sensitization model of addiction (Robinson and Berridge, 2001), which asserts that as dependence progresses, so does the salience of addiction-related cues and associated drug 'wanting'. ADS also correlated with trait Impulsivity, which is consistent with the well-established relationship between alcohol dependence and impulsivity (Finn, 2002; Limosin et al, 2003; Schuckit, 2009; von Diemen et al, 2008), and thus strengthens the external validity of the present data. The relatively stronger (inverse) correlation between SSRT to Alcohol words and ADS suggests that the severity of the dependence syndrome - a dynamic variable - better predicts the debilitating effect of salient stimuli on inhibitory control than does a stable trait like Impulsivity, although alcohol dependence per se may also involve global inhibitory deficits on the SST (Lawrence et al, 2009).

The self-report data helped to verify the effectiveness of the experimental manipulations. In the Alcohol group, the pattern of effects revealed an interaction between the effects of stress and Test Drink. When subjects expected alcohol they reported greater desire for alcohol and greater subjective stress after the active stressor than the no-stress control task. When they expected soft drink, the no-stress control was associated with greater desire for alcohol and comparable subjective stress to the active stressor. Thus, the opportunity to drink alcohol appeared to influence whether repeated success on a trivial task or repeated failure on a challenging task was associated with a stronger desire to drink.

Consumption of alcohol increased desire for alcohol more than consumption of a soft drink, consistent with the expected effects of a pharmacological prime. Consumption of alcohol or soft drink reduced subjective stress significantly, except when subjects consumed alcohol after the nostress control task. In the latter case, stress ratings increased 
after drinking, suggesting that for problem drinkers in a boring situation, consuming a modest dose of alcohol may be stressful when access to more alcohol is foreclosed.

In the P-Beer group, both desire for alcohol and subjective stress were equivalent following the active stressor and no-stress control. Consumption of placebo beer after the active stressor decreased desire to drink, whereas consumption of the soft drink did not. Consumption of placebo after the no-stress control task did not alter desire to drink, whereas consumption of a soft drink reduced it. These results contrast with those for alcohol and suggest that whereas a pharmacological prime increases incentive motivation in problem drinkers regardless of context, expectancy effects depend on whether drinking could be homeostatic (stress dampening), in which case consumption of a placebo decreases incentive motivation. Overall, the self-report data corroborate the performance data by confirming that a stressor, conditioned alcohol cues, and an alcohol prime all significantly modify motivation for alcohol and perceived stress. The self-report data also show that these factors interact in complex, sometimes counterintuitive ways.

The parallel effects of stress on Go RT and SSRT on the MSST indicate that both Go and Stop processes are susceptible to a challenge previously shown to activate the hypothalamic pituitary axis (Breier et al, 1987). This effect manifested as an increase in the impairing effects of salient $v s$ neutral stimuli on these RT indices. Such an effect is consistent with the expected increase in incentive value of alcohol under conditions that model relapse. Although 'salience' is often invoked to explain hyperreactivity to addiction-related cues and associated drug or alcohol seeking, the present findings demonstrate how salience can lead to this effect, that is, how previously inhibited behavior becomes expressed. Although there is a sizeable literature on salience and disinhibition using the modified Stroop task (Cox et al, 2006; Lusher et al, 2004; Williams et al, 1996), this finding is new to the SST paradigm.

Both inhibition and psychomotor fluency draw upon a limited pool of cognitive resources (Dywan et al, 1998; Kato et al, 2009; Krishna et al, 2006; Roncadin et al, 2007). As such, their common impairment by Alcohol words suggests that salience may reduce the ability to voluntarily allocate resources to the criterion task (Verbruggen et al, 2004). The intensification of the word type effect by stress is consistent with this explanation, as stress has been found to deplete cognitive resources (Hancock et al, 2007; Hockey, 1997; Neufeld and McCarty, 1994). At the same time, the inverse correlation between Go RT and SSRT suggests that whichever process demands fewer resources - the default response-will be enhanced at the expense of the other process. Based on the data, the Go process would appear to be favored in these circumstances. This is in line with the $3: 1$ ratio of Go to Stop trials in the task, which renders rapid response to the Go signal pre-potent. Thus, by depleting resources that permit flexible responding, salience may transform a contest between independent Go and Stop processes (ie, 'horserace') into a zero-sum game.

Of the many brain structures that may influence MSST performance, the prefrontal cortex (PFC) may be the most influential. The PFC governs multiple aspects of attention and executive control. The circuitry linking the PFC to limbic-striatal structures is engaged by stress and addictionrelated cues, and functional alterations in this circuitry are associated with relapse in addicted individuals (Sinha and Li, 2007). Compared with controls, alcohol-dependent subjects exhibit hypoactivation of PFC regions during performance of the conventional SST, and some of these deficits are associated with increased alcohol craving (Li et al, 2009). Together, the evidence suggests that incentive salience, appetitive motivation, and behavioral inhibition are sub-served by a common neural circuitry, which appears to be compromised in alcohol-dependent individuals.

The catecholamines, norepinephrine (NE) and dopamine (DA), play a pivotal role in PFC control of attention and executive function. NE, primarily through $\alpha-2$ receptors, is thought to amplify the signaling properties of salient stimuli, whereas DA, primarily through D1 receptors, is thought to screen out noise, or extraneous information (Arnsten and Li, 2005). In an animal model of the conventional SST, NE has been found to selectively mediate the Stop process, whereas DA largely mediates Go responding (Eagle et al, 2007). Phasic (burst) NE transmission in the PFC is accompanied by focused attention and behavioral stability, whereas tonic (sustained) NE transmission in the PFC promotes diffuse attention and behavioral instability (Aston-Jones et al, 1999). Stress leads to high tonic NE transmission (Abercrombie and Jacobs, 1987), and drugs that cause this effect (eg, the $\alpha-2$ NE antagonist, yohimbine) induce subjective stress-like responses in alcohol-dependent individuals, and reinstatement to alcohol seeking in animals (Krystal et al, 1996; Le et al, 2005). In healthy volunteers, yohimbine also induces a behavioral profile of impulsivity and diffuse attention similar to that of attention deficit hyperactivity disorder (ADHD) (Arnsten, 2009; Swann et al, 2005). Conversely, drugs that promote phasic NE transmission (eg, modafinil) (Minzenberg et al, 2008) restore inhibitory control and focused attention in patients with ADHD (Turner et al, 2004). By elevating tonic NE, stress may have induced an ADHD-like profile of responding in the present subjects.

The pattern of results found here suggests that stress did not cause undifferentiated impairment of attention or inhibition; the Test Drink manipulation appeared to have this more global effect. Instead, stress increased a preexisting bias in Go and Stop responding to Alcohol vs Neutral words. Alcohol-related words increase Stroop interference (ie, impede an alternative criterion response) in alcohol-dependent subjects (Stetter et al, 1995; Stormark et al, 2000). Thus, exposure to Alcohol words in the MSST may have involuntarily engaged attention in a way that impaired voluntary execution of the criterion Go response (speeded key press decision).

Addiction-related words activate the mesocorticolimbic DA system in addicted individuals (Goldstein et al, 2009). Phasic DA release is implicated in conditioned responses to drug-related cues (Phillips et al, 2003). Trial-by-trial variations in $\mathrm{RT}$ to Alcohol words in the present study suggest the operation of a rapid process, consistent with phasic DA release. Drugs that preferentially reduce tonic DA transmission at D2 receptors (haloperidol) reduce Stroop interference to drug-related words in heroin-dependent 
subjects (Franken et al, 2004). A previous account on DA and distraction (Frank and O'Reilly R, 2006) noted that 'a presynaptic increase in DA bursting by [the selective D2 antagonist] sulpiride could explain recent observations from the same group (Mehta et al, 2004) that the drug increased distractibility in a working memory task when distractors were task relevant (and could therefore elicit DA bursts and cause working memory updating) but not when distractors were irrelevant' (pp 511-512). In the present study, the Go task entailed a rapid and flexible key press response. Slowing of Go RT to Alcohol words suggests that processing the meaning of the word stimuli distracted subjects from the criterion Go response of discriminating words from non-words (lexical decision). This suggests that the Alcohol words, or more generally, the Word Type dimension, were not 'task relevant,' that is, not compatible with rapid Go RT. This would also be true for drug words in the Stroop task, and may explain the benefits of the D2 antagonist, haloperidol, in the study with heroin users (Franken et al, 2004). Together, the data suggest that phasic DA activation (primarily at D1 receptors) contributed to the adverse effects of Alcohol words on Go RT in the MSST.

The bias in Go RT to Alcohol words emerged when stress was present or absent, whereas the bias in SSRT only emerged when stress was present. Given the prominent role of NE in the Stop process (Eagle et al, 2007), the stressinduced increase in SSRT to Alcohol words could derive from high tonic NE transmission (Abercrombie and Jacobs, 1987), which would be expected to impede effortful, sustained attention (Milstein et al, 2007), particularly when the discriminative stimuli are highly salient (Ventura et al, 2008). In sum, the interaction of stress and Alcohol cues in this study suggests the operation of two interdependent processes: involuntary recruitment of attention by salient Go stimuli possibly mediated by phasic DA, and a stressinduced decrease in sustained attention to unpredictable Stop stimuli that call for inhibition, likely mediated by high tonic NE. In this way, a strong distraction coupled with a weakened ability to remain focused synergistically impaired inhibitory control to Alcohol cues.

The present study is not the first to manipulate the salience of Go stimuli in the SST. A study of light- and heavy-drinking university students found no differences in SSRT when alcohol $v s$ non-alcohol pictures served as Go stimuli (Nederkoorn et al, 2009). A second study with university students found that emotional pictures impaired both Go RT and SSRT relative to neutral pictures, and that arousal rather than valence (positive/negative) explained these effects (Verbruggen and De Houwer, 2007). The different outcomes of these two studies suggest that arousal strongly influences effects of salient Go signals in the SST. The adverse effect of arousal on Go RT and SSRT in the latter study is consistent with the pattern of effects observed here.

The primary clinical implication of the present study is that salience and inhibitory control are functionally related in problem drinkers, at least as operationalized in the MSST. This linkage suggests that treatments that reduce cue-induced craving may facilitate inhibition and vice versa. Furthermore, if the present interpretation is correct, treatments that enhance cognitive resources could conceivably reduce both craving and disinhibition. Drugs that stabilize DA transmission (eg, partial D2 agonist/antagonists) could mitigate the impact of cue-induced phasic DA signals (Myrick et al, 2010) and thereby restore flexible Go responding to Alcohol words. Reduction of tonic NE transmission by stimulating $\alpha-2$ NE receptors or enhancement of phasic NE signals by reuptake inhibition might restore sustained attention under stress, and enhance processing of stimuli that signal a need for inhibition. Such effects may, in turn, reduce the risk of relapse in the presence of stress and/or cues in alcohol-dependent individuals. The results of this study suggest that the MSST may be useful for screening potential interventions of this kind.

The present study identified the conditions that are sufficient to reveal the conjoint effects of stress and addiction-related eliciting stimuli on overt responding and inhibitory control. However, the conditions that are necessary for these effects remain to be determined. Important variables that may well moderate the Go and Stop processes include addiction status and gender, both of which have been found to affect responses to stress and cues on other cognitive indices (Chaplin et al, 2008; Fox et al, 2009; Lawrence et al, 2009; Li et al, 2009; Nesic and Duka, 2006; Udo et al, 2009). In addition, the present subjects were active drinkers and may therefore differ from individuals who have undergone treatment. Trial-by-trial topography of $\mathrm{RT}$ has also been linked with anomalies in neural function in alcohol-dependent subjects (Lawrence et al, 2009; Li et al, 2009). Coding trials to capture these temporal variations could reveal additional effects of salient stimuli. Whether similar effects are seen with other stressors, such as guided imagery (Fox et al, 2007), is another important question, given that uncontrollable noise may not fully characterize the stressful conditions that precipitate relapse outside the laboratory.

Despite these limitations, this study has provided important novel information about the relationship between salience and inhibitory control when problem drinkers are exposed to relapse-related stimuli. The findings indicate that the nature of the eliciting stimuli has a strong impact on the processes engaged. More specifically, they show that salient cues may effectively yoke the Go and Stop processes in the horserace model, and that factors like stress, which increase the incentive value of addictive reinforcers, can augment the disruptive effects of salient stimuli on intentional behavior in male problem drinkers.

\section{ACKNOWLEDGEMENTS}

This study was partially funded by a grant from the Canadian Institutes of Health Research to LAZ and UEB.

\section{DISCLOSURE}

The authors declare no conflict of interest.

\section{REFERENCES}

Abercrombie ED, Jacobs BL (1987). Single-unit response of noradrenergic neurons in the locus coeruleus of freely moving 
cats.I Acutely presented stressful and nonstressful stimuli. J Neurosci 7: 2837-2843.

Andres P (2003). Frontal cortex as the central executive of working memory: time to revise our view. Cortex 39: 871-895.

Arnsten AF (2009). Toward a new understanding of attention-deficit hyperactivity disorder pathophysiology: an important role for prefrontal cortex dysfunction. CNS Drugs 23: 33-41.

Arnsten AF, Li BM (2005). Neurobiology of executive functions: catecholamine influences on prefrontal cortical functions. Biol Psychiatry 57: 1377-1384.

Aston-Jones G, Rajkowski J, Cohen J (1999). Role of locus coeruleus in attention and behavioral flexibility. Biol Psychiatry 46: 1309-1320.

Band GP, van der Molen MW, Logan GD (2003). Horse-race model simulations of the stop-signal procedure. Acta Psychol (Amst) 112: 105-142.

Beck AT, Beck RW (1972). Screening depressed patients in family practice. A rapid technic. Postgrad Med 52: 81-85.

Bissett PG, Nee DE, Jonides J (2009). Dissociating interferencecontrol processes between memory and response. J Exp Psychol Learn Mem Cogn 35: 1306-1316.

Bjork JM, Hommer DW, Grant SJ, Danube C (2004). Impulsivity in abstinent alcohol-dependent patients: relation to control subjects and type 1-/type 2-like traits. Alcohol 34: 133-150.

Boucher L, Palmeri TJ, Logan GD, Schall JD (2007). Inhibitory control in mind and brain: an interactive race model of countermanding saccades. Psychol Rev 114: 376-397.

Breier A, Albus M, Pickar D, Zahn TP, Wolkowitz OM, Paul SM (1987). Controllable and uncontrollable stress in humans: alterations in mood and neuroendocrine and psychophysiological function. Am J Psychiatry 144: 1419-1425.

Brown D, Fenwick P, Howard R (1989). The contingent negative variation in a Go/No Go avoidance task: relationships with personality and subjective state. Int J Psychophysiol 7: 35-45.

Chaplin TM, Hong K, Bergquist K, Sinha R (2008). Gender differences in response to emotional stress: an assessment across subjective, behavioral, and physiological domains and relations to alcohol craving. Alcohol Clin Exp Res 32: 1242-1250.

Cox WM, Fadardi JS, Pothos EM (2006). The addiction-Stroop test: theoretical considerations and procedural recommendations. Psychol Bull 132: 443-476.

Crews FT, Boettiger CA (2009). Impulsivity, frontal lobes and risk for addiction. Pharmacol Biochem Behav 93: 237-247.

Dywan J, Segalowitz SJ, Webster L (1998). Source monitoring: ERP evidence for greater reactivity to nontarget information in older adults. Brain Cogn 36: 390-430.

Eagle DM, Bari A, Robbins TW (2008). The neuropsychopharmacology of action inhibition: cross-species translation of the stop-signal and go/no-go tasks. Psychopharmacology (Berl) 199: 439-456.

Eagle DM, Tufft MR, Goodchild HL, Robbins TW (2007). Differential effects of modafinil and methylphenidate on stopsignal reaction time task performance in the rat, and interactions with the dopamine receptor antagonist cis-flupenthixol. Psychopharmacology (Berl) 192: 193-206.

Eisenberg DT, Mackillop J, Modi M, Beauchemin J, Dang D, Lisman SA et al (2007). Examining impulsivity as an endophenotype using a behavioral approach: a DRD2 TaqI A and DRD4 48-bp VNTR association study. Behav Brain Funct 3: 2.

Evenden JL (1999). Varieties of impulsivity. Psychopharmacology (Berl) 146: 348-361.

Eysenck HJ, Eysenck SBG (1969). Personality Structure and Measurement. Routledge: London.

Field M, Mogg K, Bradley BP (2005). Craving and cognitive biases for alcohol cues in social drinkers. Alcohol Alcohol 40: 504-510.

Field M, Quigley M (2009). Mild stress increases attentional bias in social drinkers who drink to cope: a replication and extension. Exp Clin Psychopharmacol 17: 312-319.
Field M, Schoenmakers T, Wiers RW (2008). Cognitive processes in alcohol binges: a review and research agenda. Curr Drug Abuse Rev 1: 263-279.

Fillmore MT, Rush CR, Hays L (2006). Acute effects of cocaine in two models of inhibitory control: implications of non-linear dose effects. Addiction 101: 1323-1332.

Finn PR (2002). Motivation, working memory, and decision making: a cognitive-motivational theory of personality vulnerability to alcoholism. Behav Cogn Neurosci Rev 1: 183-205.

Finn PR, Justus A, Mazas C, Steinmetz JE (1999). Working memory, executive processes and the effects of alcohol on Go/ No-Go learning: testing a model of behavioral regulation and impulsivity. Psychopharmacology (Berl) 146: 465-472.

Fischman MW, Foltin RW (1991). Utility of subjective-effects measurements in assessing abuse liability of drugs in humans. $\mathrm{Br}$ J Addict 86: 1563-1570.

Fox HC, Bergquist KL, Hong KI, Sinha R (2007). Stress-induced and alcohol cue-induced craving in recently abstinent alcoholdependent individuals. Alcohol Clin Exp Res 31: 395-403.

Fox HC, Hong KI, Siedlarz KM, Bergquist K, Anderson G, Kreek MJ et al (2009). Sex-specific dissociations in autonomic and HPA responses to stress and cues in alcohol-dependent patients with cocaine abuse. Alcohol Alcohol 44: 575-585.

Frank MJ, O’Reilly R C (2006). A mechanistic account of striatal dopamine function in human cognition: psychopharmacological studies with cabergoline and haloperidol. Behav Neurosci 120: 497-517.

Franken IH, Hendriks VM, Stam CJ, Van den Brink W (2004). A role for dopamine in the processing of drug cues in heroin dependent patients. Eur Neuropsychopharmacol 14: 503-508.

Furlanetto LM, Mendlowicz MV, Romildo Bueno J (2005). The validity of the Beck Depression Inventory-Short Form as a screening and diagnostic instrument for moderate and severe depression in medical inpatients. J Affect Disord 86: 87-91.

Goldstein RZ, Tomasi D, Alia-Klein N, Honorio Carrillo J, Maloney T, Woicik PA et al (2009). Dopaminergic response to drug words in cocaine addiction. J Neurosci 29: 6001-6006.

Goldstein RZ, Volkow ND (2002). Drug addiction and its underlying neurobiological basis: neuroimaging evidence for the involvement of the frontal cortex. Am J Psychiatry 159: $1642-1652$.

Grusser SM, Wrase J, Klein S, Hermann D, Smolka MN, Ruf M et al (2004). Cue-induced activation of the striatum and medial prefrontal cortex is associated with subsequent relapse in abstinent alcoholics. Psychopharmacology (Berl) 175: 296-302.

Hancock PA, Ross JM, Szalma JL (2007). A meta-analysis of performance response under thermal stressors. Hum Factors 49: 851-877.

Hartley LR, Adams RG (1974). Effect of noise on the Stroop test. J Exp Psychol 102: 62-66.

Heinz A, Siessmeier T, Wrase J, Hermann D, Klein S, Grusser SM et al (2004). Correlation between dopamine $\mathrm{D}(2)$ receptors in the ventral striatum and central processing of alcohol cues and craving. Am J Psychiatry 161: 1783-1789.

Hester R, Dixon V, Garavan H (2006). A consistent attentional bias for drug-related material in active cocaine users across word and picture versions of the emotional Stroop task. Drug Alcohol Depend 81: 251-257.

Hockey GR (1997). Compensatory control in the regulation of human performance under stress and high workload; a cognitive-energetical framework. Biol Psychol 45: 73-93.

Kamarajan C, Porjesz B, Jones KA, Choi K, Chorlian DB, Padmanabhapillai A et al (2005). Alcoholism is a disinhibitory disorder: neurophysiological evidence from a Go/No-Go task. Biol Psychol 69: 353-373.

Kato Y, Endo H, Kizuka T (2009). Mental fatigue and impaired response processes: event-related brain potentials in a Go/NoGo task. Int J Psychophysiol 72: 204-211. 
Krishna BS, Steenrod SC, Bisley JW, Sirotin YB, Goldberg ME (2006). Reaction times of manual responses to a visual stimulus at the goal of a planned memory-guided saccade in the monkey. Exp Brain Res 173: 102-114.

Krystal JH, Webb E, Cooney NL, Kranzler HR, Southwick SW, Heninger GR et al (1996). Serotonergic and noradrenergic dysregulation in alcoholism: $\mathrm{m}$-chlorophenylpiperazine and yohimbine effects in recently detoxified alcoholics and healthy comparison subjects. Am J Psychiatry 153: 83-92.

Kucera H, Francis WN (1967). Computational Analysis of PresentDay American English. Brown University Press: Providence, RI.

Lawrence AJ, Luty J, Bogdan NA, Sahakian BJ, Clark L (2009). Impulsivity and response inhibition in alcohol dependence and problem gambling. Psychopharmacology (Berl) 207: 163-172.

Le AD, Harding S, Juzytsch W, Funk D, Shaham Y (2005). Role of alpha-2 adrenoceptors in stress-induced reinstatement of alcohol seeking and alcohol self-administration in rats. Psychopharmacology (Berl) 179: 366-373.

Li CS, Huang C, Yan P, Bhagwagar Z, Milivojevic V, Sinha R (2008). Neural correlates of impulse control during stop signal inhibition in cocaine-dependent men. Neuropsychopharmacology 33: 1798-1806.

Li CS, Luo X, Yan P, Bergquist K, Sinha R (2009). Altered impulse control in alcohol dependence: neural measures of stop signal performance. Alcohol Clin Exp Res 33: 740-750.

Limosin F, Loze JY, Dubertret C, Gouya L, Ades J, Rouillon F et al (2003). Impulsiveness as the intermediate link between the dopamine receptor D2 gene and alcohol dependence. Psychiatr Genet 13: 127-129.

Logan GD, Schachar RJ, Tannock R (1997). Impulsivity and inhibitory control. Psychological Sci 8: 60-64.

Lusher J, Chandler C, Ball D (2004). Alcohol dependence and the alcohol Stroop paradigm: evidence and issues. Drug Alcohol Depend 75: 225-231.

Martin CS, Earleywine M, Finn PR, Young RD (1990). Some boundary conditions for effective use of alcohol placebos. J Stud Alcohol 51: 500-505.

Mehta MA, Manes FF, Magnolfi G, Sahakian BJ, Robbins TW (2004). Impaired set-shifting and dissociable effects on tests of spatial working memory following the dopamine D2 receptor antagonist sulpiride in human volunteers. Psychopharmacology (Berl) 176: 331-342.

Milstein JA, Lehmann O, Theobald DE, Dalley JW, Robbins TW (2007). Selective depletion of cortical noradrenaline by antidopamine beta-hydroxylase-saporin impairs attentional function and enhances the effects of guanfacine in the rat. Psychopharmacology (Berl) 190: 51-63.

Minzenberg MJ, Watrous AJ, Yoon JH, Ursu S, Carter CS (2008). Modafinil shifts human locus coeruleus to low-tonic, highphasic activity during functional MRI. Science 322: $1700-1702$.

Mulvihill LE, Skilling TA, Vogel-Sprott M (1997). Alcohol and the ability to inhibit behavior in men and women. J Stud Alcohol 58: 600-605.

Myrick H, Li X, Randall PK, Henderson S, Voronin K, Anton RF (2010). The effect of aripiprazole on cue-induced brain activation and drinking parameters in alcoholics. $J$ Clin Psychopharmacol 30: 365-372.

Nederkoorn C, Baltus M, Guerrieri R, Wiers RW (2009). Heavy drinking is associated with deficient response inhibition in women but not in men. Pharmacol Biochem Behav 93: 331-336.

Nesic J, Duka T (2006). Gender specific effects of a mild stressor on alcohol cue reactivity in heavy social drinkers. Pharmacol Biochem Behav 83: 239-248.

Neufeld RW, McCarty TS (1994). A formal analysis of stressor and stress-proneness effects on simple information processing. Br J Math Stat Psychol 47: 193-226.
Newman JP, Widom CS, Nathan S (1985). Passive avoidance in syndromes of disinhibition: psychopathy and extraversion. J Pers Soc Psychol 48: 1316-1327.

Noel X, Van der Linden M, d'Acremont M, Bechara A, Dan B, Hanak C et al (2007). Alcohol cues increase cognitive impulsivity in individuals with alcoholism. Psychopharmacology (Berl) 192: 291-298.

Phillips PE, Stuber GD, Heien ML, Wightman RM, Carelli RM (2003). Subsecond dopamine release promotes cocaine seeking. Nature 422: 614-618.

Richell RA, Anderson M (2004). Reproducibility of negative mood induction: a self-referent plus musical mood induction procedure and a controllable/uncontrollable stress paradigm. J Psychopharmacol 18: 94-101.

Robinson TE, Berridge KC (2001). Incentive-sensitization and addiction. Addiction 96: 103-114.

Roncadin C, Pascual-Leone J, Rich JB, Dennis M (2007). Developmental relations between working memory and inhibitory control. J Int Neuropsychol Soc 13: 59-67.

Rubia K, Russell T, Overmeyer S, Brammer MJ, Bullmore ET, Sharma $\mathrm{T}$ et al (2001). Mapping motor inhibition: conjunctive brain activations across different versions of go/no-go and stop tasks. Neuroimage 13: 250-261.

Samson J, Sheeladevi R, Ravindran R, Senthilvelan M (2007). Stress response in rat brain after different durations of noise exposure. Neurosci Res 57: 143-147.

Schuckit MA (2009). An overview of genetic influences in alcoholism. J Subst Abuse Treat 36: S5-14.

Shaham Y, Shalev U, Lu L, De Wit H, Stewart J (2003). The reinstatement model of drug relapse: history, methodology and major findings. Psychopharmacology (Berl) 168: 3-20.

Sinha R, Li CS (2007). Imaging stress- and cue-induced drug and alcohol craving: association with relapse and clinical implications. Drug Alcohol Rev 26: 25-31.

Skinner HA, Allen BA (1982). Alcohol dependence syndrome: measurement and validation. J Abnorm Psychol 91: 199-209.

Skinner HA, Horn JL (1984) Addiction Research Foundation: Toronto.

Sobell LC, Brown J, Leo GI, Sobell MB (1996). The reliability of the alcohol timeline followback when administered by telephone and by computer. Drug Alcohol Depend 42: 49-54.

Stetter F, Ackermann K, Bizer A, Straube ER, Mann K (1995). Effects of disease-related cues in alcoholic inpatients: results of a controlled 'Alcohol Stroop' study. Alcohol Clin Exp Res 19: 593-599.

Stewart J (2008). Review. Psychological and neural mechanisms of relapse. Philos Trans $R$ Soc London B Biol Sci 363: 3147-3158.

Stormark KM, Laberg JC, Nordby H, Hugdahl K (2000). Alcoholics' selective attention to alcohol stimuli: automated processing? J Stud Alcohol 61: 18-23.

Swann AC, Birnbaum D, Jagar AA, Dougherty DM, Moeller FG (2005). Acute yohimbine increases laboratory-measured impulsivity in normal subjects. Biol Psychiatry 57: 1209-1211.

Townshend JM, Duka T (2007). Avoidance of alcohol-related stimuli in alcohol-dependent inpatients. Alcohol Clin Exp Res 31: 1349-1357.

Turner DC, Clark L, Dowson J, Robbins TW, Sahakian BJ (2004). Modafinil improves cognition and response inhibition in adult attention-deficit/hyperactivity disorder. Biol Psychiatry 55: 1031-1040.

Udo T, Bates ME, Mun EY, Vaschillo EG, Vaschillo B, Lehrer P et al (2009). Gender differences in acute alcohol effects on selfregulation of arousal in response to emotional and alcoholrelated picture cues. Psychol Addict Behav 23: 196-204.

Ventura R, Latagliata EC, Morrone C, La Mela I, Puglisi-Allegra S (2008). Prefrontal norepinephrine determines attribution of 'high' motivational salience. PLoS One 3: e3044. 
Verbruggen F, De Houwer J (2007). Do emotional stimuli interfere with response inhibition? Evidence from the stop signal paradigm. Cogn Emotion 21: 391-403.

Verbruggen F, Liefooghe B, Vandierendonck A (2004). The interaction between stop signal inhibition and distractor interference in the flanker and Stroop task. Acta Psychol (Amst) 116: 21-37.

Verbruggen F, Logan GD (2009). Models of response inhibition in the stop-signal and stop-change paradigms. Neurosci Biobehav Rev 33: 647-661.

Vogel-Sprott M (1992). Guilford: New York.

Volkow ND, Fowler JS, Wang GJ, Swanson JM (2004). Dopamine in drug abuse and addiction: results from imaging studies and treatment implications. Mol Psychiatry 9: 557-569.

von Diemen L, Bassani DG, Fuchs SC, Szobot CM, Pechansky F (2008). Impulsivity, age of first alcohol use and substance use disorders among male adolescents: a population based casecontrol study. Addiction 103: 1198-1205.
Wilkinson DA, LeBreton S (eds) (1986). Plenum: New York.

Williams JM, Mathews A, MacLeod C (1996). The emotional Stroop task and psychopathology. Psychol Bull 120: 3-24.

Wilson MD (1988). The MRC Psycholinguistic Database: Machine Readable Dictionary, Version 2 Behav Res Methods Instrum Comput 20: 6-11.

Winer B (1971). Statistical Principles in Experimental Design, 2nd edn. McGraw-Hill: New York.

Witkiewitz K, Marlatt GA (2007). Modeling the complexity of posttreatment drinking: it's a rocky road to relapse. Clin Psychol Rev 27: 724-738.

Zack M, Toneatto T, MacLeod CM (1999a). Clinical use of benzodiazepines and decreased memory activation in anxious problem drinkers. Alcohol Clin Exp Res 23: 174-182.

Zack M, Toneatto T, MacLeod CM (1999b). Implicit activation of alcohol concepts by negative affective cues distinguishes between problem drinkers with high and low psychiatric distress. J Abnorm Psychol 108: 518-531.

Supplementary Information accompanies the paper on the Neuropsychopharmacology website (http://www.nature.com/npp) 